\title{
Análise das relações sino-brasileiras a partir da prisão de nove chineses no início do governo militar (1964)
}

Celiane Ferreira da Costa ${ }^{l}$

Resumo: O artigo visa abordar o momento de aproximação e afastamento nas relações políticas entre Brasil e República Popular da China no início da década de 1960. Tomando como referência o caso de nove chineses que foram presos no Brasil quando os militares assumiram o governo, em 1964, é possível traçar um panorama de como se desenvolveram as relações sino-brasileiras no referido período. Esse momento de aproximação foi de extrema importância na construção das relações sino-brasileiras, que seriam estabelecidas em 1974. A análise baseia-se documentos emitidos pelo Ministério das Relações Exteriores e bibliografia sobre o tema.

Palavras-Chave: Brasil. China. Relações Políticas. Prisão de chineses.

\section{Analysis of Chinese-Brasilian relations starting with the arrested of nine Chineses at the beginning of the military government (1964)}

Abstract: The article aims to approach the moment of approximation and distance in political relations between Brazin and People's Republic of China in the early 1960's. Taking as reference the case in which nine Chinese were arrested in Brazil when the

\footnotetext{
${ }^{1}$ Mestrado em andamento na Universidade Federal do Paraná, departamento de História, linha de pesquisa Cultura e Poder. Pesquisadora discente no Núcleo de Estudos Mediterrânicos (NEMED/UFPR). Especialista em História Contemporânea e Relações Internacionais pela Pontifícia Universidade Católica do Paraná (2012). Licenciada em História pela Pontifícia Universidade Católica do Paraná (2010). E-mail: celi_cwb@hotmail.com
} 
$|8|$

Análises das relações sino-brasileiras...

military took over the government in 1964, it is possible to outline a picture of how Sino-Brazilian relations developed in that period. This moment of approximation was of extreme importance in the construction of Sino-Brazilian relations, which would be established in 1974. The analysis is based on documents issued by the Ministry of Foreign Affairs and bibliography on the subject.

Keywords: Brazil. China. Political Relations. Chinese prisoners.

\section{Análises de las relaciones chino-brasileñas a partir de la prisión de nueve chinos as inicio del gobierno militar (1964)}

Resumen: El artículo busca abordar el momento de aproximación y alejamiento en las relaciones políticas entre Brasil y la República Popular de China a principios de la década de 1960. Tomando como referencia el caso de nueve chinos que fueron arrestados en Brasil cuando los militares asumieron el gobierno, en 1964, es posible trazar un panorama de cómo se desarrollaron las relaciones sino-brasileñas en el referido período. Este momento de aproximación fue de extrema importancia en la construcción de las relaciones sino-brasileñas, que serían establecidas en 1974. El análisis se basa en documentos emitidos por el Ministerio de Relaciones Exteriores y bibliografía sobre el tema.

Palabras-clave: Brasil. China. Relaciones políticas. Prisión de los chinos.

\section{Introdução}

A China é atualmente o maior parceiro comercial do Brasil e o estudo das relações sino-brasileira vem se tornando mais recorrente no meio acadêmico brasileiro. Há vários estudos que se ocupam de abordar o tema seja no campo da Economia, do Direito, Meio Ambiente, Sociologia, Antropologia e/ou Relações Internacionais. O estudo das relações sino-brasileiras no campo da História, se dedicam a analisar, grosso modo, o período posterior ao estabelecimento das relações diplomáticas, em 1974. O período que antecede o estabelecimento das relações diplomáticas ainda é pouco estudado. Sendo assim, esse artigo visa analisar um importante período das relações entre Brasil e China, no início da década de 1960. 
O Brasil não reconheceu a República Popular da China, instaurada por Mao Tsé-tung em 1949, pois mantinha relações diplomáticas com a República da China² desde 1912. Após a proclamação da República Popular da China, o governo nacionalista, liderado por Chiang Kai-shek foi transferido para Taiwan e o Brasil retirou a Embaixada que havia sido transferida para Xangai.

Nesse período o Brasil era governado pelo general Eurico Gaspar Dutra, na presidência do país desde 1946. Durante seu governo (1946-1951), início da Guerra Fria, Dutra mantém o Brasil alinhado com os interesses estadunidenses, mantendo-se na esfera do capitalismo e afastando-se de qualquer influência socialista/ comunista. No campo externo, o Brasil rompeu suas relações diplomáticas com a URSS, em 1947 e não reconheceu o governo comunista de Kim Il-sung instaurado na Coreia do Norte em 1948.

$\mathrm{O}$ artigo versa sobre a aproximação e o brusco rompimento das relações sino-brasileiras a partir da prisão de nove chineses que se encontravam no Brasil quando os militares assumiram o poder, em 1964. A prisão dos chineses teve repercussão mundial, sendo noticiado por vários jornais estrangeiros como o primeiro caso de violação dos direitos humanos do governo militar (GUEDES; MELO, 2014, p. 119). Vejamos de que forma se deu a aproximação entre o Brasil e a China.

\footnotetext{
${ }^{2}$ Com a proclamação da República Popular da China, em $1^{\circ}$ de outubro de 1949, a China se divide em República Popular da China (RPC) e República da China, resultado da polarização das forças políticas que disputavam o controle do país (os comunistas e os nacionalistas). Liderados por Mao Tsétung, os comunistas assumiram o controle da China dando início à RPC, com capital em Pequim. Outros termos como China Popular, China Continental, China Comunista e governo de Pequim, são usados como sinônimos à RPC. No tocante à República da China, sediada em Taiwan, existem também os sinônimos: China Nacionalista, Taiwan, governo de Taipé e Formosa. Optouse por utilizar ao longo deste artigo a sigla RPC, ou apenas China, para referirse à República Popular da China e China Nacionalista ou Taiwan quando se referir à República da China.
} 


\section{A Política Externa Independente e a aproximação com a China}

Foi durante o período em que adotou a Política Externa Independente - doravante PEI - de 1961 à 1964, que o Brasil buscou aproximar as relações com a RPC. Nesse período o Brasil era governado por Jânio Quadros, que em seu breve mandato, apresentou ao Congresso Nacional uma mensagem sobre a PEI, onde colocava o Brasil em posição de negociação do estabelecimento ou restabelecimento de relações diplomáticas com países socialistas.

San Tiago Dantas ${ }^{3}$, no seu livro Política Externa Independente ${ }^{4}$, destaca os pontos que nortearam a PEI: "contribuição à preservação da paz através, da prática da coexistência e do apoio ao desarmamento geral e progressivo" (2011, p. 10), que pode ser percebido, com o posicionamento do Brasil na Conferência do Desarmamento em Genebra, realizada em março de 1962, onde o Brasil aparece como país não-alinhado e se posiciona contra os testes nucleares realizados pela União Soviética; "reafirmação e fortalecimento dos princípios de não intervenção e autodeterminação dos povos" (Ibidem, loc. cit), princípio que foi defendido pelo Brasil na Conferência de Punta del Este ${ }^{5}$,

${ }^{3}$ San Tiago Dantas foi Ministro das Relações Exteriores no período de setembro de 1961 à julho de 1962, sendo precedido e sucedido por Afonso Arinos. É considerado um dos principais formuladores da Política Externa Independente.

${ }^{4}$ O livro Política Externa Independente foi originalmente publicado em 1962 e há uma versão disponível no site: http://www.santiagodantas.com.br e que pode ser acessado pelo link: http://www.santiagodantas.com.br/wp-content/ uploads/politica_externa_independente.pdf. Acesso em: 20 jun. 2018. A Fundação Alexandre de Gusmão publicou uma versão atualizada do livro em 2011, disponível em: http://funag.gov.br/loja/download/839-PolItica_Externa_ Independente.pdf. Acesso em: 20 jun. 2018. Optou-se, para este artigo, por utilizar a versão da FUNAG de 2011.

${ }^{5}$ Denominação pela qual ficou conhecida a VIII Reunião de Consulta dos Ministros das Relações Exteriores da Organização dos Estados Americanos (OEA), realizada em Punta del Este, Uruguai, entre 22 e 31 de janeiro de 1962. 
quando votou contra a expulsão de Cuba da Organização dos Estados Americanos (OEA); "ampliação do mercado externo brasileiro mediante o desarmamento tarifário da América Latina e a intensificação das relações comerciais com todos os países, inclusive os socialistas" (DANTAS, 2011, p. 10), ponto sobre o qual San Tiago Dantas destaca:

Com relação aos países socialistas, o Ministério das Relações Exteriores fez tudo que se achava ao seu alcance para criar uma linha de intercâmbio, que deve adaptar-se, para lograr pleno êxito, ao tipo de transações característico dos sistemas de economia centralmente planificada. Nenhuma possibilidade de crescimento existe nessa área se o Brasil desejar esquivar-se às regras do comércio bilateral, planejando com as autoridades dos países socialistas, ao mesmo tempo, a compra e a venda de seus respectivos produtos. (DANTAS, 2011, p. 15).

Conforme visto anteriormente, durante a vigência da PEI o Brasil buscou estreitar relações com países socialistas. O presidente Jânio Quadros mostrava-se favorável a discussão sobre a inclusão RPC na Organização das Nações Unidas (ONU) (GARCIA, 2008, p. 504). Jânio Quadros, ainda solicitou ao Ministério das Relações Exteriores, que fosse organizado um grupo de trabalho que se designasse, com exclusividade a examinar os problemas internacionais do Brasil com relação, entre outras coisas, à China Popular (GARCIA, 2008, p. 511). Ainda durante seu breve mandato, foi organizada a Missão Comercial do Brasil à República Popular da China, em agosto de 1961, que se fez para retribuir a visita da uma Missão chinesa feita ao Brasil em maio de 1961, "que aqui esteve com a finalidade de explorar as possibilidades de

Fonte: FGV. Conferência de Punta del Este. In: Dicionário Histórico-Biográfico Brasileiro - DHBB. Rio de Janeiro: FGV-CPDOC (Verbete). Disponível em: http://www.fgv.br/cpdoc/acervo/dicionarios/verbete-tematico/punta-deleste-conferencia-de. Acesso em: 21 jun. 2018. 
intercâmbio comercial Brasil-República Popular da China (DINIZ, 1962, p. 1) ${ }^{6}$.

Em bilhete enviado ao Ministério das Relações Exteriores e ao Ministério da Indústria e Comércio, no dia 19 de maio de 1961, o presidente Jânio Quadros pede que seja organizada uma "missão de alto nível" e sugere que o embaixador João Augusto de Araújo Castro, creditado em Tóquio, seja incluído como conselheiro (BILHETES..., 2006, p. 408). Em memorando enviado ao Secretário Geral das Relações Exteriores, no dia 24 de julho de 1961, o Chefe do Departamento Político e Cultural, Carlos S. de Ouro Preto destaca que a Missão deve manter o caráter estritamente comercial e econômico, evitando abordar, assuntos políticos com os chineses. (OURO PRETO, 1961). A partir desses dois documentos é possível concluir que o presidente do Brasil queria organizar uma Missão notória, de reconhecida importância. Para tal, nomeou o vicepresidente da República, João Goulart, para chefiá-la. Já o Itamaraty canalizava seus esforços para que a Missão mantivesse seu caráter comercial, sem adotar tons políticos, uma vez que o Brasil ainda mantinha relações diplomáticas com a China Nacionalista e qualquer missão de caráter político poderia ser visto como um desrespeito à autoridade de Taiwan.

O embaixador João Augusto de Araújo Castro, subchefe da Missão Comercial brasileira à China, redigiu um relatório onde apresenta os bastidores da viagem à China. Araújo Castro deixa transparecer em seu relatório a dificuldade em manter o caráter comercial da Missão, pelo fato dela ser chefiada pelo vicepresidente do Brasil, o que dava a Missão caráter cada vez mais político. Ao chegar em Pequim, a Missão brasileira foi recebida pelo vice-presidente Pi-Wu. Araújo Castro destaca que eram os chineses que buscavam dar a maior solenidade possível à abertura das negociações comerciais, enquanto ele tentava, em vão, manter o caráter comercial da Missão:

${ }^{6}$ Quanto à utilização das fontes, serão feitas as transcrições tais quais os documentos, utilizando os grifos originais, e respeitando a grafia comum à época, para garantir a fidedignidade do documento. 
Fiz, sem qualquer êxito, o impossível para levar o Vice-Presidente a pedir aos chineses que evitassem dar forma tão solene a coisa tão simples: a negociação de um acôrdo de pagamentos, entre o Banco do Brasil e o Banco Popular da China. [...] E, assim, as conversações foram abertas com a presença de um Vice-Presidente da República e de um Vice-Primeiro Ministro. Poucos Tratados internacionais receberam tratamento tão exaltado (CASTRO, 1961b, p. 17-18).

A viagem resultou na assinatura do Ajuste Interbancário entre o Brasil e a China, que apresenta os fatos relativos à possibilidade e viabilidade de um fluxo regular de comércio entre China e Brasil, através do Banco Popular da China e o Banco do Brasil. De acordo com Vizentini (1995, p. 215), o Brasil exportaria matérias-primas como café, cacau, algodão, couro e lã; óleos vegetais, madeira, bens industriais de consumo e a China, em contrapartida, exportaria máquinas-ferramentas, perfuratrizes, carvão, chumbo, zinco, aço, matérias-primas farmacêuticas, bens industriais de consumo, artesanato, etc.

A viagem de João Goulart à China teve de ser interrompida pois Jânio Quadros renunciou justamente no período em que Goulart, visto como adepto dos ideais comunistas, visitava a República Popular da China. Jânio Quadros acreditava que sua renúncia não seria aceita, e isso ampliaria seus poderes. No entanto a renúncia foi aceita, e a direita civil e militar, que almejava conquistar o poder desde 1954, manifestou-se contrária à posse do vice, João Goulart (VIZENTINI, 2008, p. 25-26).

Para resolver o impasse sobre a posse ou não de João Goulart, foi adotado o sistema parlamentarista e Tancredo Neves assumiu o cargo de Primeiro-Ministro. Com essa solução a direita esperava limitar os poderes de João Goulart e evitar que o Brasil caminhasse rumo ao socialismo. Durante o governo de Goulart, a PEI passou a sofrer cada vez mais limitações. Mas as relações com a China, ainda que tímidas, eram mantidas. Segundo Cervo (1994, p. 334) em 1962 o Brasil recebeu a visita de uma delegação do Banco da China e em 1963, foi autorizada a abertura de um escritório comercial chinês no Brasil. 


\section{A prisão dos chineses e o afastamento das relações sino- brasileiras}

O golpe militar de 1964, que depôs João Goulart, significou a interrupção no processo de aproximação das relações sinobrasileiras. Em setembro de 1964 o Congresso Nacional rejeitava o acordo comercial com a RPC, assinado durante a Missão Comercial de agosto de 1961. Mas o ponto mais crítico nas relações com a China foi a prisão de nove chineses, no dia 3 de abril de 1964, dois dias depois do golpe militar. Os nove chineses que estavam aqui no Brasil, eram: dois jornalistas, Wang Wei-Chen e Chu ChingTung, que estavam no Brasil desde 29 de dezembro de 1961; quatro membros da Missão encarregada de organizar uma exposição de objetos chineses, Su Tzu-Ping, Hou Fa-Tseng, Wang Chih e Chang Pao-Sheng, que chegaram em junho de 1963; e três membros de uma missão comercial, Wang Yao-Ting, Mao Yao-Tseng e Sung Kuei-Pao, que chegaram ao Brasil em janeiro de 1964.

A vinda dos jornalistas chineses foi negociada durante a viagem de João Goulart à China. Um dia antes de encerrar a visita oficial à RPC, no dia 23 de agosto de 1961, João Goulart solicitou que Araújo Castro enviasse um telegrama a Secretaria de Estado das Relações Exteriores, para que fossem tomadas as medidas necessárias para a concessão dos vistos para Wang Wei-Chen e Chu Ching-Tung (CASTRO, 1961a).

No dia 26 de agosto de 1961, a Secretaria de Estado das Relações Exteriores enviou um telegrama para o Consulado Geral em Zurique concedendo visto oficial válido por 30 dias para os jornalistas Wang Wei-Chen e Chu Ching-Tung (VISTO..., 1961). Em decorrência da renúncia do presidente Jânio Quadros, o Itamaraty solicitou ao Conselho Geral de Zurique que aguardasse novas instruções quanto ao visto dos jornalistas. Por fim, no dia 26 de novembro de 1961, a Secretaria de Estado envia novas instruções para o Consulado de Paris, para que seja concedido aos jornalistas chineses visto temporário, válido por um ano (OLIVEIRA; CAVALCANTI; FRIEDRICH, 1964, p. 3-4). Os vistos foram autorizados pelo então Ministro das Relações Exteriores, San Tiago Dantas. 
Os jornalistas desembarcaram no Brasil no dia 29 de dezembro de 1961, e tão logo chegaram foram ao encontro do assessor de imprensa do Itamaraty, Dario de Castro Alves, no início de janeiro de 1962, requerer a credencial de jornalistas estrangeiros. Essa credencial era normalmente concedida aos jornalistas apresentados pelas Embaixadas dos países de onde eram naturais. Seguindo essa regra a credencial não poderia ser concedida aos jornalistas, uma vez que o Brasil e a China não mantinham relações diplomáticas. Dario de Castro Alves, apresenta uma exceção à regra, o caso do correspondente da Agência Telegráfica da União Soviética (TASS, sigla em russo), sr. Artiushenkov, que recebeu a credencial antes do restabelecimento das relações diplomáticas entre Brasil e União Soviética. Mas no caso dos chineses, conceder as credenciais poderia prejudicar as relações com a China Nacionalista. Posto isso, Castro Alves argumenta que seria ilógico conceder visto de um ano e não conceder as credenciais de jornalistas para os chineses atuarem no país. O mais sensato teria sido negar os vistos a esses jornalistas (ALVES, 1962, p. 1-2). Em resposta, o Ministro Paulo Leão de Moura, Secretário Geral Adjunto para Assuntos de Europa Oriental e Ásia argumenta:

5. A meu ver, a um representante de Agência noticiosa oficial de um país com o qual não mantemos, nem, como tudo indica, esperamos estabelecer relações diplomáticas, deveria ser negada a credencial solicitada, que certamente poderia servir a seus beneficiários como primeiro passo ao estabelecimento de tal agência em território nacional, que me parece indesejável por motivos políticos óbvios (Ibidem, p. 3-4).

O Ministro do MRE, San Tiago Dantas concordou em não conceder as credenciais aos jornalistas, para evitar imbróglios com a China Nacionalista. A presença dos jornalistas chineses passa a ser monitorada pelo Conselho de Segurança Nacional, conforme sugere Celso Diniz, chefe da DAO, em memorando do dia 7 de agosto de 1962 (AIDE-MEMÓIRE, [1962?]). No tempo em 
que estiveram no Brasil, mesmo sem as credenciais de trabalho, os jornalistas escreveram por volta de 2.500 reportagens sobre o Brasil. As reportagens eram enviadas por telégrafo para Londres, de onde eram retransmitidas para Pequim (GUEDES; MELO, 2014, p. 56).

A Embaixada em Berna encaminhou à Secretaria de Estado, no dia 4 de abril de 1963, o pedido de concessão de visto para o segundo grupo de chineses que vieram ao Brasil, encarregados de organizar a Exposição Comercial da China no Brasil. O grupo era comporto por Hou Fa-Tseng, líder da comitiva, Su Tzu-Ping, Wang Chih e Chang Pao-Sheng, intérprete do grupo, pois falava fluentemente o português. A Secretaria de Estado respondeu no dia seguinte, 5 de abril, que a exposição era considerada inoportuna, portanto os vistos deveriam ser negados (EXPOSIÇÃO..., 1963a).

Inconformados com a decisão, outro telegrama foi enviado à Secretaria de Estado solicitando a concessão dos vistos. Outra resposta negativa: o telegrama, do dia 3 de maio de 1963, informava que não havia se alterado a posição do governo brasileiro quanto a exposição. Na terceira tentativa, sem saber como negar novamente os vistos, uma vez que a Exposição havia sido autorizada tanto por Jânio Quadros, como por João Goulart, a Secretaria de Estado do MRE tomou uma medida incomum. Em telegrama enviado para a Embaixada de Berna, no dia 22 de maio de 1963, o Itamaraty concedia vistos temporários aos chineses, mas ainda mantinha a posição contrária à realização da Exposição (EXPOSIÇÃO..., 1963b). Ou seja, os membros do grupo encarregado de organizar a Exposição Comercial de produtos da China, poderiam vir ao Brasil, mas não poderiam montar a Exposição. Esse segundo grupo chegou ao Brasil no dia 6 de junho de 1963.

Foi evocando o acordo Interbancário, assinado durante a viagem de João Goulart à China, que o jornalista Wang Wei Chen procurou o Chefe da Divisão de Ásia e Oceania (DAO), Armindo Branco Mendes Cadaxa, para interceder em favor da realização da exposição comercial de produtos da China, rogando que a realização da exposição seria de grande valia para fomentar o comércio entre os dois países. Além disso, as autoridades chinesas 
tinham a intenção de manter um representante do comércio exterior chinês, para facilitar os contatos entre importadores e exportadores. O Chefe da DAO mostrou-se favorável à realização da exposição, bem como à manutenção de um representante comercial chinês no Brasil, conforme o memorando enviado para Aluysio Regis Bittencourt, Secretário Geral Adjunto para Assuntos da Europa Oriental e Ásia, em 14 de junho de 1963:
5. No tocante à Exposição comercial e industrial como é do conhecimento de Vossa Excelência, superiores autoridades brasileiras haviam considerado inoportuna, por enquanto, a sua realização. Permito- me opinar no sentido de que, uma vez desapercebida tal inoportunidade, seria útil que a Exposição tivesse lugar [...]. Essa ordem de razões seria aplicável à permanência de um agente comercial das organizações chinesas de comércio exterior (CADAXA, 1963, p.2).

Considerada inoportuna diversas vezes, a Exposição foi autorizada pelo presidente João Goulart no dia 31 de janeiro de 1964. O Ministro do MRE, João Augusto de Araújo Castro, envia ao Ministro da Indústria e do Comércio um memorando informando que o presidente autorizará a realização da Exposição, que poderia ser nas cidades Niterói-RJ e/ou Belo Horizonte-MG (CASTRO, 1964). A Exposição, que deveria acontecer em maio do mesmo ano, não foi realizada em decorrência do Golpe Militar, deflagrado em abril de 1964.

Em 20 de novembro de 1963, a Embaixada do Brasil em Londres concedeu os vistos para Wang Yao-Ting, vice-diretor da Companhia Chinesa para Exportação e Importação de Têxteis (China Tex), chefe da equipe, Mao Yao-Tseng, classificador de algodão e Sung Kuei-Pao, intérprete fluente em inglês. Esse último grupo seria responsável por comprar algodão no Brasil (GUEDES; MELO, 2014, p. 65-66). Wang Yao-Ting já tinha estado no Brasil em 1956 para comprar um lote de algodão de uma empresa paulista, mas a transação não chegou a se concretizar. Em 1964 a compra do algodão esbarrou num problema cambial: 


\begin{abstract}
O acordo interbancário assinado em agosto de 1961, em Pequim, havia estabelecido uma taxa de câmbio fixa para as trocas comerciais em libras esterlinas que, por conta da inflação, se desvalorizou rapidamente. Em 1964, o preço negociado pela taxa do câmbio convênio, como relata Wang Yoating em seu depoimento à Justiça Militar, era 50\% menor do que o do câmbio livre da libra esterlina na época, o que inviabilizou as negociações com as empresas privadas (Ibidem, p. 66).
\end{abstract}

Os chineses conseguiram negociar a compra de 4 toneladas de algodão, mas para finalizar a transação faltavam 20 mil dólares, para fazer o transporte do algodão para o porto de onde seria embarcado o produto. Wang Yao-Ting solicitou ao jornalista Wang Wei-Chen que trouxesse o dinheiro, uma vez que este se encontrava na China e retornaria ao Brasil no início de março de 1964 (Ibidem, loc. cit). Assim como a Exposição dos produtos chineses, a compra do algodão não chegou a se concretizar em decorrência do golpe civil-militar de 1964.

Os militares assumiram o governo do Brasil em de abril de 1964. João Goulart havia se retirado de Brasília em direção à Porto Alegre. O presidente da Câmara do Deputados, Ranieri Mazzilli assumiu a presidência do Brasil. Em pouco dias, cerca de 4 mil pessoas foram presas sob a suspeita de serem comunistas. Acusados de atividades subversivas, os chineses foram presos no dia 3 de abril de 1964.

O prédio em que vivam os jornalistas Wang Wei-Chen e Chu Ching-Tung, e os comerciantes Mao Yao-Tseng e Su Tzu-Ping começou a ser vigiado no dia 2 de abril. Os policiais cercaram o prédio e no início do dia 3 de abril invadiram o apartamento e prenderem os quatro chineses (GUEDES, MELO, 2014, p. 19-21). Em entrevista concedida aos autores Ciça Guedes e Murilo Fiuza de Melo em 2013, o jornalista Chu Ching-Tung relata que os chineses foram espancados pelos policiais ainda no apartamento (Ibidem, p. 227). Concomitantemente, outra equipe policial seguia para o prédio onde moravam os outros cinco chineses, que foram presos e levados às dependências do DOPS. Numa coletiva de imprensa, 
realizada ainda no dia 3 de abril, o secretário de Segurança da Guanabara, coronel Gustavo Borges, dava detalhes dos planos dos chineses:

Para subverter a ordem política do país, os chineses contavam, dizia ele, com armas pouco usuais: agulhas envenenadas, comprimidos letais e pipas com "bombas teleguiadas em forma de pássaros". As tais pipas, apelidadas por Borges de "Dragão de Fogo", eram montadas com "pequenos foguetes levando bananas de dinamite" (GUEDES; MELO, 2014, p. 92).

No dia seguinte à prisão dos chineses, o jornal Diário de Notícias $^{7}$, do Rio de Janeiro, dava informações mais detalhadas de como se daria a atuação dos chineses no plano de tomar o controle político do Brasil e implementar o comunismo:

A China de Mao Tsé mandou ao Brasil nove homens com a incumbência de assassinar o sr. Carlos Lacerda e os generais Amauri Kruel e Castelo Branco. Iam usar no crime o chamado "processo chinês": uma injeção indolor que fulmina instântaneamente, e que seria aplicada no momento em que o criminoso se aproximasse da vítima simulando um encontrão.

As "armas" descritas pelos policiais do DOPS, eram na verdade agulhas de acupuntura e o "Dragão de Fogo" era um desenho antigo de um foguete chinês. Na mesma edição do dia 4 de abril, do jornal Diário de Notícias, era informado que os chineses possuíam a quantidade de $\mathrm{Cr} \$ 110$ milhões em dólares e libras ${ }^{8}$. O

${ }^{7}$ DIÁRIO DE NOTÍCIAS. MAO TSE MANDOU MATAR À CHINESA. Diário de Notícias, Rio de Janeiro, 4 abr. 1964. p. 1. Disponível em: http://memoria. bn.br/DocReader/093718_04/37684. Acesso em: 28 jun. 2018.

${ }^{8}$ DIÁRIODE NOTÍCIAS. ESPIÕES CHINESESIAMASSASSINAR LACERDA, KRUEL E CASTELO BRANCO. Diário de Notícias, Rio de Janeiro, 4 abr. 1964. p.10. Disponível em: http://memoria.bn.br/DocReader/093718_04/37693. 
valor informado na guia de recolhimento ao Banco do Brasil, no entanto, era bem menor. Um mês depois do recolhimento do valor, os valores informados ao Banco do Brasil foram assim descritos: “189.022 cruzeiros, 49.277 dólares americanos, 2.260 francos suícos, 138 libras, 3 rublos, e 3 kopekas, além de um cheque da Union Bank of Switzerland de 2.500 francos suíços. Corrigido, o dinheiro representaria hoje R\$877.756,61" (GUEDES; MELO, 2014, p. 9394). Os chineses contestaram, alegando que eles possuíam mais dinheiro do que o valor discriminado. Segundo eles, a diferença seria de pouco mais de $\mathrm{R} \$ 40.000,00$. Descontando cerca de $\mathrm{R} \$$ 12.000,00, usado para cobrir despesas de alimentos, cigarros e medicamentos dos chineses presos, e parte da hospedagem das esposas dos chineses que vieram visitá-los, o restante do valor não foi devolvido para os chineses (GUEDES; MELO, 2014, p. 94).

No dia 13 de abril, Hou Fa-Tseng, Su Tzu-Ping e Mao YaoTseng foram transferidos para o $1^{\circ}$ Batalhão de Guardas, em São Cristóvão; Wang Wei-Chen, Wang Yao-Ting, Chang Pao-Sheng e Wang Chih foram levados ao $1^{\circ}$ Batalhão de Polícia do Exército; Chu Ching-Tung e Sung Kuei-Pao permaneceram no DOPS (Ibidem, p. 101). No dia 22 de abril, os presos chineses receberam a visita do Embaixador paquistanês, Syed Mawbuli Murshed, do presidente da OAB, Carlos Povina Cavalcanti, e o representante da Cruz Vermelha no Brasil, Eric Haegler, para constatar as condições físicas dos chineses, que confirmaram não haver indícios de maustratos aos presos. Após essa visita os chineses ficaram juntos no $1^{\mathrm{o}}$ Batalhão de Guardas, por quase sete meses, até serem separados em três grupos novamente em 11 de novembro de 1964 .

Os chineses realizaram, durante o período de detenção, duas greves de fome. A primeira foi feita logo no início da detenção, no dia 4 de abril e durou três dias. Essa greve começou quando um general anunciou que os chineses seriam enviados no dia 6 de abril para Taiwan (Ibidem, p. 99). A greve terminou quando foi anunciado publicamente que os chineses não seriam enviados para Taiwan. A segunda greve de fome durou do dia 13 ao dia

Acesso em: 28 jun. 2018. 
16 de novembro. Essa greve decorre da separação dos presos que aconteceu, conforme dito anteriormente, no dia 11 de novembro. Para acabar com a greve, o advogado Heráclito Sobral Pinto se comprometeu a fazer protestos junto às autoridades e mobilizar os meios de comunicação. A greve de fome não deu resultados positivos e os nove chineses ficaram separados até o momento que foram expulsos do Brasil.

Durante o período em que ficaram detidos no Brasil, as esposas de alguns dos chineses puderam visitá-los, em duas ocasiões. O Auxiliar do Chefe do Departamento de Assuntos Jurídicos, Guido Fernando Silva Soares, redigiu um relatório sobre o período em que aconteceram as primeiras visitas. De acordo com o relatório, o primeiro grupo de visita era composto por esposas de três chineses, acompanhadas pelo representante da Sociedade Chinesa da Cruz Vermelha, senhor Yi Chengsin. Os chineses chegaram ao Brasil em 24 de agosto de 1964, dia em que foi realizada a primeira visita. As visitas eram acompanhadas por Eric Haegler, representante do Comitê Internacional da Cruz Vermelha, Guido Fernando Silva Soares, representante do Departamento de Assuntos Jurídicos, e autoridades do Exército. Foram realizadas no total 10 visitas, sendo 8 dos casais individualmente e 2 de conjunto com os outros 6 presos. As visitas aconteceram entre os dias 24 de agosto e 8 de setembro, dia em que os chineses partiram do Aeroporto do Galeão com destino a Genebra. Guido Soares conclui o relatório da seguinte maneira:

132. [...] pode dizer-se que as visitas tiveram os resultados queridos: deixar às claras, tanto em relação à Cruz Vermelha Chinesa quanto à Cruz Vermelha Internacional, que o tratamento dos detidos é, no Brasil, conforme as regras de qualquer país civilizado do mundo, o que vem a desmentir, de frente, os boatos tendenciosos e distorsivos da imprensa internacional (SOARES, 1964, p. 21). 
Guido Soares ainda ressalta que a neutralização das notícias "falaciosas" poderiam, de alguma maneira, acarretar resultados positivos para as relações internacionais do Brasil, uma vez que os próprios representantes da Cruz Vermelha atestaram as boas condições em que se encontravam os presos chineses.

O segundo grupo chegou para visitar os chineses no dia 29 de janeiro de 1965. Eram as esposas de quatro prisioneiros, o representante da Sociedade Chinesa da Cruz Vermelha, Wang Min, e um intérprete. Guido Soares também redigiu um relatório sobre as visitas. Foram um total de onze visitas, em todas elas estavam presentes Eric Haegler, representante do Comitê Internacional da Cruz Vermelha e o próprio Guido Soares, como representante do Itamaraty. Das onze visitas, os senhores Wang Min e o intérprete só participaram de cinco visitas. Isso, devido ao acontecido na terceira visita, realizada no dia 4 de fevereiro, quando Wang Min fez um discurso que não agradou as autoridades presentes. Em um dos trechos do discurso, que depois de ser traduzido 9 foi enviado ao Itamaraty, Wang Min afirmava que o tratamento dispensado aos chineses detidos era injusto e ilegal, por estes serem inocentes. Dado o tom político do discurso e das acusações proferidas por Wang Min, ele e o intérprete foram impedidos de participar das demais visitas. Guido Soares finaliza o relatório buscando mostrar a benevolência do governo brasileiro, conforme segue:

61. De seis visitas previstas, foram realizadas onze, a fim de atender ao pedido do representante da Cruz Vermelha Chinesa. Da duração de meia hora, estendeuse o prazo para uma hora inteira, igualmente para acceder [sic] a pedido daquela pessoa. E de tudo isso foi informado o Senhor Wang Min, que o que se fazia era por liberalidade, e em atenção à Cruz Vermelha, cujas finalidades o Brasil muito respeitara (SOARES, 1965, p. 17).

\footnotetext{
${ }^{9}$ As visitas eram gravadas e depois enviadas para um tradutor indicado pelo DOPS.
} 
O segundo grupo que viera visitar os presos chineses, deixou o Brasil em 12 fevereiro de 1965. O Itamaraty havia concedido visto de mais quinze dias para as esposas dos chineses detidos, mas o mesmo não foi concedido ao intérprete nem à Wang Min. As quatro chinesas optaram por não permanecer no Brasil sem a presença do intérprete e do representante da Sociedade Chinesa da Cruz Vermelha.

O julgamento do caso começou no dia 21 de dezembro de 1964 mas sem esperanças de conseguir a liberdade dos chineses. O julgamento foi acompanhado por juristas de várias partes do mundo. Sobre tal aspecto do julgamento, o jornal Correio da Manhã, do Rio de Janeiro, noticiava no dia 22 de dezembro:

\begin{abstract}
[A]conteceu o que nunca ainda acontecera no Brasil comissões de juristas estrangeiros assistem ao processo para observar o funcionamento da justiça militar brasileira, assim como juristas estrangeiros assistiram a processos políticos na Rússia czarista ou em países coloniais despoticamente governados. ${ }^{10}$
\end{abstract}

Após 15 horas e meia de julgamento, às 6 h30 do dia 22 de dezembro de 1964 a sentença foi finalmente anunciada: dez anos de prisão pelo crime de subversão. Sobral Pinto recorreu alegando inconsistência jurídica ao enquadrar os chineses no artigo $2^{\underline{0}}$ da Lei de Segurança Nacional, sobre subversão. "Segundo o artigo, o crime constituía-se em 'tentar mudar a ordem política e social estabelecida pela Constituição' [...]. Em suas 'Razões da Apelação', Sobral mostra que em nenhum momento houve uma ação dos chineses nesse sentido" (GUEDES; MELO, 2014, p. 164-165). O pedido foi negado.

No dia 16 de janeiro de 1965, o ministro da Justiça, Milton Campos, enviou ao presidente da República um parecer

${ }^{10}$ CORREIO DA MANHÃ. LEGALIDADE USURPADA - GOVERNO. Correio da Manhã, Rio de Janeiro, 22 dez. 1964. p. 6. Disponível em: http://memoria. bn.br/DocReader/089842_07/58852. Acesso em: 24 jun. 2018. 
que concluía pela expulsão dos nove chineses. Castelo Branco assinou o decreto de expulsão, no dia 26 de fevereiro de 1965. Em telegrama enviado à Embaixada do Brasil em Berna, no dia 19 de abril de 1965, a Secretaria de Estado das Relações Exteriores comunicou que "partiram dia 18 do corrente, [...] os nove chineses integrantes da suposta missão comercial, condenados pela Justiça militar brasileira, e expulsos do Território nacional" (PARTIDA..., 1965 , p. 1). Os chineses foram recebidos na China pelo então viceprimeiro-ministro Li Xianninan, que se desempenharia mais tarde as funções de presidente da República.

Alguns dos chineses ocuparam posições de destaque nos anos seguintes. Conforme Guedes e Melo (2014, p. 179-180), Wang Wei-Chen se tornou diretor-geral da agência Xinhua; Wang YaoTing virou presidente do Conselho Chinês para Promoção do Comércio Internacional; Hou Fa-Tseng foi nomeado diretor-geral adjunto do gabinete do Ministério do Comércio Exterior; e Chang Pao-Sheng se tornou Embaixador da China em Moçambique. Em 2014, ano em que o livro $O$ caso dos nove chineses, foi publicado, dos nove chineses, cinco ainda estavam vivos, todos com mais de 80 anos. Apesar da repercussão internacional do caso dos nove chineses, atualmente esse episódio não é conhecido pelas novas gerações de chineses.

\section{Conclusão}

Com a adoção da Política Externa Independente, no início do governo do Presidente Jânio Quadros, em 1961, houve a aproximação entre Brasil e China. O Brasil recebeu em maio de 1961, uma equipe chinesa que buscava explorar as possibilidades de intercâmbio comercial entre Brasil e China. Em retribuição a essa visita, o presidente Jânio Quadros, organizou uma missão comercial, enviada a China em agosto de 1961 e chefiada pelo vice-presidente João Goulart. Nessa viagem, foi assinado o Ajuste Interbancário entre o Brasil e a China, para viabilizar o fluxo regular de comércio entre os dois países. 
Para facilitar as transações comerciais entre Brasil e China, os chineses postularam organizar uma exposição de produtos chineses, para tal vieram ao Brasil, em junho de 1963, quatro chineses. Em janeiro do ano seguinte chegou ao Brasil um grupo de três chineses, membros de uma missão comercial. Já estavam aqui no Brasil, desde dezembro de 1961, dois jornalistas, que enviavam para a China notícias sobre o Brasil.

Os nove chineses tiveram suas atividades monitoradas desde que chegaram ao Brasil. Quando os militares assumiram o governo do Brasil, em abril de 1964, os nove chineses foram presos, acusados de espionagem e subversão. Ainda em 1964, o Brasil rejeitava o Ajuste Interbancário assinado com a China. A relação de proximidade com a China foi então rompida. Os chineses ficaram presos por um ano. Segundo relato do jornalista Chu Ching-Tung, eles sofreram torturas durante o período de detenção. No entanto, o representante do Comitê Internacional da Cruz Vermelha atestou que os chineses estavam sendo mantidos em boas condições, e que nas visitas que fez, não identificou indícios de maus-tratos.

O julgamento dos chineses aconteceu em dezembro de 1964. Eles foram acusados de crime de subversão e condenados a dez anos de prisão. Em fevereiro de 1965, o presidente Castelo Branco decretou a expulsão dos chineses, que deixaram o Brasil no dia 18 de abril de 1965.

O episódio da prisão dos chineses foi um momento de tensão nas relações sino-brasileiras. Acusação de torturas, o dinheiro dos chineses que não foi devolvido, a condenação, tudo isso deixou por muito tempo a percepção de um imbróglio mal resolvido. Em dezembro de 2014, depois de 50 anos, o governo brasileiro reconheceu o erro histórico cometido contra os nove chineses. Uma portaria do Ministério da Justiça revogou o decreto de março de 1965 e no dia 12 de agosto de 2015, os nove chineses foram condecorados com a medalha da Ordem do Cruzeiro do Sul, a mais alta insígnia do Brasil. 


\section{Referências}

BILHETES DO PRESIDENTE JÂNIO QUADROS AO MINISTÉRIO DAS RELAÇÕES EXTERIORES. In: Cadernos do CHDD. Brasília: Fundação Alexandre de Gusmão, ano V, n. 8, p. 313-484, 2006. Disponível em: http://funag.gov.br/loja/download/333-Cadernos_do_ CHDD_N_08.pdf. Acesso em: 21 jun. 2018.

CERVO, A. L. (org.). O Desafio Internacional: a política exterior do Brasil de 1930 a nossos dias. Brasília: Editora Universidade de Brasília, 1994.

DANTAS, S. T. Política externa independente. Brasília: Fundação Alexandre de Gusmão, 2011. Disponível em: http://funag.gov.br/loja/ download/839-PolItica_Externa_Independente.pdf. Acesso em: 20 jun. 2018.

FGV. Conferência de Punta del Este. In: Dicionário HistóricoBiográfico Brasileiro - DHBB. Rio de Janeiro: FGV-CPDOC (Verbete). Disponível em: http://www.fgv.br/cpdoc/acervo/dicionarios/ verbete-tematico/punta-del-este-conferencia-de. Acesso em: 21 jun. 2018.

GARCIA, E. V. (org.). Diplomacia brasileira e política externa: documentos históricos (1493-2008). Rio de Janeiro: Contraponto, 2008 .

GUEDES, C.; MELO, M. F. de. O caso dos nove chineses: O escândalo internacional que transformou vítimas da ditadura militar brasileira em heróis de Mao Tsé-tung. Rio de Janeiro: Editora Objetiva, 2014.

VIZENTINI, P. F. Relações internacionais e desenvolvimento: o nacionalismo e a política externa independente 1951-1964. Petrópolis: Editora Vozes, 1995.

VIZENTINI, P. F. Relações internacionais do Brasil: de Vargas a Lula. São Paulo: Fundação Perseu Abramo, 2008. 
Documentos - Arquivo do Ministério das Relações Exteriores (Itamaraty) Brasília-DF.

AIDE-MEMÓIRE. Rio de Janeiro, [jul. 1962?]. Seção de Correspondência Confidencial, Caixa 5, Estante 581, Prateleira 2.

ALVES, D. de C. Memorandum para o Sr. Chefe do Gabinete. Rio de Janeiro, 3 jan. 1962. Seção de Correspondência Confidencial, Caixa 5, Estante 581, Prateleira 2.

CADAXA, Armindo Branco Mendes. Relações econômicas BrasilRepública Popular da China. Brasília, 14 jun. 1963. Seção de Correspondência Especial, Memoranda Confidencial, 1963.

CASTRO, J. A. de A. Visto em passaporte. Wang Wei Shung. Chu Cing Sung. Pequim, 23 ago. 1961a. Seção de Correspondência Confidencial, Caixa 5, Estante 581, Prateleira 2.

CASTRO, J. A. de A. Relatório Político da Missão Comercial do Brasil à República Popular da China. Hong Kong, 4 set. 1961b. Seção de Correspondência Especial, Ofícios: Consulados e Delegações (1950/59), Ano: 1950/63, Caixa ํำ 18

CASTRO, J. A. de A. Exposição da República Popular da China. Rio de Janeiro, 31 jan. 1964. Seção de Correspondência Confidencial, Caixa 5, Estante 581, Prateleira 2.

DINIZ, Celso. Vinda ao Brasil de Missão comercial da República Popular da China. Rio de Janeiro, 28 ago. 1962. Seção de Correspondência Especial, Memoranda Confidencial, 1962 (jul a dez).

EXPOSIÇÃO DA REPÚBLICA POPULAR DA CHINA NO BRASIL. PEDIDO DE VISTOS. Rio de Janeiro, 5 abr. 1963a. Seção de Correspondência Confidencial, Caixa 5, Estante 581, Prateleira 2.

EXPOSIÇÃO DA REPÚBLICA POPULAR DA CHINA NO BRASIL. PEDIDO DE VISTO. Rio de Janeiro, 22 mai. 1963b. Seção de Correspondência Confidencial, Caixa 5, Estante 581, Prateleira 2. 
OLIVEIRA, A. C. de; CAVALCANTI, T. B.; FRIEDRICH, L. da C. Missões comerciais e jornalistas da China Continental (Comunista). Relatório. Rio de Janeiro, 17 jun. 1964. Seção de Correspondência Confidencial, Caixa 5, Estante 581, Prateleira 2.

OURO PRETO, Carlos S. de. Missão Comercial à China. Rio de Janeiro, 24 jul. 1961. Seção de Correspondência Especial, Circulares, Despachos, Notas, Ofícios Expedidos, Pareceres e Memoranda. Embaixadas, Consulados, Diversos no Brasil. Ano: 1961/62. Caixa ${ }^{\mathrm{o}}$ 33.

PARTIDA DOS 9 CHINESES CONDENADOS PELA JUSTIÇA MILITAR. Rio de Janeiro, 19 abr. 1965. Seção de Correspondência Confidencial, Caixa 5, Estante 581, Prateleira 2.

SOARES, G. F.S. Visita de 3 senhoras chinesas que, acompanhadas de um representante da Cruz Vermelha chinesa vieram ver seus maridos, presos e à disposição da Justiça Militar. Rio de Janeiro, 14 set. 1964. Seção de Correspondência Confidencial, Caixa 5, Estante 356, Prateleira 1.

SOARES, G. F. S. Visita de 4 senhoras chinesas acompanhadas de um representante da Sociedade chinesa da Cruz Vermelha e um intérprete. Rio de Janeiro, 8 mar. 1965. Seção de Correspondência Confidencial, Caixa 5, Estante 356, Prateleira 1.

VISTO OFICIAL. WANG WEI SHUNG. CHU CING SUNG. Rio de Janeiro, 26 ago. 1961. Seção de Correspondência Confidencial, Caixa 5, Estante 581, Prateleira 2.

Fontes de Imprensa

CORREIO DA MANHÃ. LEGALIDADE USURPADA GOVERNO. Correio da Manhã, Rio de Janeiro, 22 dez. 1964. p. 6. <Disponível em: http://memoria.bn.br/DocReader/089842_07/58852>. Acesso em: 24 jun. 2018. 
DIÁRIO DE NOTÍCIAS. MAO TSE MANDOU MATAR À CHINESA. Diário de Notícias, Rio de Janeiro, 4 abr. 1964. p. 1. <Disponível em: http://memoria.bn.br/DocReader/093718_04/37684>. Acesso em: 28 jun. 2018.

DIÁRIO DE NOTÍCIAS. ESPIÕES CHINESES IAM ASSASSINAR LACERDA, KRUEL E CASTELO BRANCO. Diário de Notícias, Rio de Janeiro, 4 abr. 1964. p. 10. Disponível em: <http://memoria. bn.br/DocReader/093718_04/37693>. Acesso em: 28 jun. 2018. 
